\title{
Los avances del grupo PASO en el estudio de la poesía áurea, el canon y su posterior recepción
}

\author{
Gáldrick de la Torre Ávalos \\ Universitat de Girona \\ galdric.t.a@gmail.com
}

Gómez Canseco, Luis; Montero, Juan; Ruiz Pérez, Pedro (eds.)

Aurea poesis. Estudios para Begoña López Bueno en el 25 aniversario del Grupo PASO.

Córdoba, Servicio de Publicaciones, Universidad de Córdoba; Sevilla, Secretariado de

Publicaciones, Universidad de Sevilla; Huelva, Servicio de Publicaciones, Universidad de Huelva; 2014, 437 p.

ISBN 978-84-9927-154-5

ISBN 978-84-472-1533-1

ISBN 978-84-15633-19-8

López Bueno, Begoña (ed.)

Entre sombras y luces. La recepción de la poesía del Siglo de Oro de 1700 a 1850

Sevilla, Universidad de Sevilla, 2014, 362 p. Literatura; 136.

ISBN 978-84-472-1595-9

Las aportaciones del grupo PASO (Poesía Andaluza del Siglo de Oro) han significado, como es de sobra conocido, un antes y un después en los estudios de la lírica española áurea, por lo que es de justicia recordar aquí, por brevemente que sea, los momentos clave de su trayectoria; con más motivo aún si se tiene en cuenta que, de los dos volúmenes para comentar, el primero es un homenaje a la propia trayectoria del grupo, iniciada ya hace más de veinticinco años, y que tanto uno como otro señalan bien las dos etapas que la han caracterizado.

La primera empieza en el ańo 1988, cuando Begoña López Bueno funda el proyecto. La idea original era crear un grupo de investigación que analizara los 
géneros líricos de la poesía del Siglo de Oro teniendo en cuenta los rasgos que los definían en su tiempo: aspectos como la métrica, el estilo y la finalidad en cada uno de ellos; se planteaba así un doble estudio que aunara la perspectiva diacrónica con una visión pluridimensional que sirviera para poner límites a los distintos géneros y que permitiera ofrecer un panorama representativo de la realidad literaria española. Fruto de este empeño fue la celebración de una serie de Encuentros Internacionales que tuvieron lugar entre 1990 hasta prácticamente entrado el ańo 2002. Unos encuentros que se basaron en las aportaciones de los distintos miembros del grupo y que se enriquecieron con la presencia de varios especialistas que fueron invitados en cada ocasión. Como resultado del diálogo entre unos y otros, se publicaron cinco volúmenes de carácter monográfico centrados cada uno de ellos en los distintos géneros y titulados de forma homónima (siguiendo la secuencia temporal): La silva (1991), La oda (1993), La elegía (1996), La epistola (2000) y La égloga (2002), todos publicados bajo el sello editorial de la Universidad de Sevilla e incorporados más tarde al volumen digital La poesía del Siglo de Oro. Géneros y modelos. Se cerraba así una primera etapa que dio lugar a un segundo momento en la vida del grupo.

A partir del año 2001, hasta llegar al 2013, PASO empieza a interesarse por el problema historiográfico de la conformación del canon de la lírica áurea, y lo hace con un proyecto de revisión sistemática de las distintas recepciones de la poesía del Siglo de Oro, comenzando por la de los propios poetas y acabando con la lectura que hicieron de su obra los historiógrafos modernos. Del mismo modo que ocurría en la anterior serie, se llevaron a cabo varios Encuentros Internacionales que culminaron también con la publicación de otros cuatro volúmenes. Más adelante nos detendremos en el contenido de cada uno de ellos al mencionar el contexto del volumen que cierra la serie.

Gómez Canseco, Luis; Montero, Juan; Ruiz Pérez, Pedro (eds.) Aurea poesis. Estudios para Begoña López Bueno en el 25 aniversario del Grupo PASO. Córdoba, Servicio de Publicaciones, Universidad de Córdoba; Sevilla, Secretariado de Publicaciones, Universidad de Sevilla; Huelva, Servicio de Publicaciones, Universidad de Huelva; 2014, 437 p.

ISBN 978-84-9927-154-5

ISBN 978-84-472-1533-1

ISBN 978-84-15633-19-8

El volumen titulado Aurea poesis. Estudios para Begoña López Bueno constituye un homenaje a la propia trayectoria del grupo con motivo del vigesimoquinto aniversario. Por esta razón, reúne unos contenidos que se hallan en clara sintonía con las dos líneas de investigación antes mencionadas. Ahora bien, lo interesante del volumen es que supone un homenaje por partida doble; en efecto, se celebran los veinticinco años de la creación del grupo, pero este se iguala y no 
se concibe sin la presencia de Begońa López Bueno, quien, además de ser su fundadora, ha sido durante la práctica totalidad de su andadura, su directora. Es por eso que, en última instancia, el volumen está dedicado a ella, en un gesto de agradecimiento en el que colaboran, además de los autores del libro - la mayoría miembros del grupo PASO o participantes de los congresos internacionales-, sus editores, así como discípulos de López Bueno, Luis Gómez Canseco, Pedro Ruiz Pérez y Juan Montero.

En tanto, pues, que se trata de un homenaje que implica al grupo pero que atañe también a su fundadora, los trabajos aquí reunidos se relacionan con varios aspectos de la obra de López Bueno y también con los volúmenes ya publicados. Así, nos encontramos con artículos que abordan las formas y los géneros poéticos del Siglo de Oro, como el de Blanca Perinán, «Algo más sobre la "forma-chiste" "; trabajos relacionados con la formación del canon, como los de Ángel Estévez e Isabel Román, y un amplio abanico de contribuciones de lo más variado que se centran en los principales poetas del Siglo de Oro y en especial en los de la escuela sevillana: los de Núñez Rivera, Galbarro García, entre otros. Por lo general, se trata de artículos breves que trabajan algún aspecto concreto de la poesía áurea, y en algún caso, aunque pocos, también de la prosa.

La idea que inspira el volumen es básicamente la misma que caracteriza los Encuentros Internacionales: el diálogo. Este se presenta como una recopilación de trabajos de variada índole, pero que quedan unificados por el hecho de formar parte de una reflexión conjunta en artículos que se agrupan bajo distintas áreas temáticas; de ahí que los artículos sean breves. Todos abordan aspectos muy concretos pero originales, como si se diera la lección por aprendida, en un volumen que no pretende ser pedagógico y que directamente va a los detalles. Pongamos por ejemplo el artículo que Nadine Ly dedica a la figura del hápax como recurso literario en la obra de Góngora; un aspecto de la misma que no se ha estudiado y que deja abierta la posibilidad de una nueva investigación (de la que, en este caso, se ocupará la autora). Igual que el de Ly, los demás artículos abordan aspectos concretos que, en algunos casos, invitan a estudios más profundos. En ese sentido, todo el libro parece una historia de la poesía del Siglo de Oro hecha desde los márgenes, con aspectos que permiten ahondar en la materia y que son fruto de ese diálogo entre especialistas.

En cuanto a la ordenación del volumen - y para ir entrando en materia-, sigue la misma que los anteriores, editados bajo la dirección de Begoña López Bueno. Por esta razón, el homenaje no solo afecta al contenido, sino que atañe también a las formas. Se trata de su manera de editar; una manera que se caracteriza por emplear una ordenación lógica y coherente, basada en el uso de criterios cronológicos y temáticos que, en este caso, alternan las aportaciones de los miembros del grupo con aquellas de los especialistas invitados.

A continuación, se señalan los distintos apartados en que se dividen los artículos tomando en consideración para tales efectos dichos criterios cronológicos y temáticos. 
Hay un primer bloque dedicado a la poesía sin autor y a los géneros populares en el que se incluye, además del ya citado trabajo de Blanca Perinán, los de Cristina Moya García y Giuseppe di Stefano. Empezando por este último — de hecho, el que abre el libro-, se titula «Para la historia textual del romancero: los pliegos sueltos de Perugia». Di Stefano analiza el manuscrito encontrado por Víctor Infantes en el ańo 2013 en la Biblioteca Comunale Augusta de Perugia y se centra en los pliegos numerados del 28 al 33, incluyendo el 35, para estudiar los romances que se contienen en ellos y su relación con la literatura de cordel. Se trata de un total de 36 romances que llaman la atención por el hecho de que parece haber entre ellos cierta unidad temática; al menos en los romances que salieron de la imprenta de Juan Navarro. Di Stefano sugiere que el editor pudo haber publicado esta serie dada su familiaridad con el antologista y también autor de romances Juan de Timoneda, quien previamente había impreso allí algunas de sus colecciones (p. ej., la Flor de enamorats, 1556). El estudio resalta algunas de las peculiaridades internas y también externas de los poemas incluidos en el manuscrito e introduce como apéndice un cotejo con otros textos y versiones extraídas de la tradición (también las que aparecen en los libros de Timoneda). Por su parte, el artículo de Cristina Moya García se enmarca dentro del estudio de las relaciones entre literatura y antroponimia medieval castellana, estudio que durante mucho tiempo ha servido para conocer la presencia de otras tradiciones en territorio peninsular; en este caso, de la tradición árabe y andalusí. La autora toma el ejemplo de doña Catalina de Perea, vecina de la localidad sevillana de Utrera que vivió durante el primer cuarto del siglo xvi. Doña Catalina tuvo tres esclavas moras a las que dio el nombre de Axa, Fátima y Marién. Basándose en el nombre de las esclavas, García Moya plantea la posibilidad de que doña Catalina tuviera en cuenta para la selección onomástica el conocido villancico sobre las morillas de Jaén: «Tres moricas me enamoran / en Jaén: / Axa, Fátima y Marién». El último artículo, el de Blanca Periñán, lleva por título "Algo más sobre la "forma-chiste"». Se trata, en buena medida, de una réplica o de una corrección de un trabajo anterior en el que también la autora abordaba el estudio del chiste. ${ }^{1}$ Periñán establece la diferencia entre el sentido concreto que tiene la palabra hoy y el significado que tenía en la España del siglo xvi: una forma estrófica cercana a la oralidad, de tres versos octosilábicos y un último con el pie quebrado, que se utilizaba generalmente para poemas de carácter discursivo y de tipo popular, los cuales no necesariamente eran cómicos. Esta constituye, por así decir, la primera parte o la parte introductoria del artículo, donde Perinán intenta también rastrear los orígenes de esta forma estrófica vinculándola a otras variedades italianas como la barzelleta, la frottola y el gliommero napolitano. La segunda parte del artículo se centra en cuatro chistes, que aparecen en los ya citados pliegos de Perugia y que la autora edita teniendo en cuenta la previa definición. textos, Pisa, Giardini, 1970. 
El siguiente grupo de artículos es el más nutrido de la colección. Está constituido por un amplio abanico de trabajos que se relacionan con la obra de los principales poetas del Siglo de Oro y de algunos menos conocidos del Bajo Barroco. Siguiendo el orden cronológico, abren la serie dos estudios sobre Garcilaso: uno de Valentín Núnez Rivera y otro de Jaime Galbarro García, a los que sigue el escrito por Antonio Carreira sobre el poeta Luis de Camôes. El artículo de Núñez Rivera «Garcilaso en mejor orden (1543-1765)» estudia la ordenación que ha recibido el corpus poético de Garcilaso de la Vega a través de sus varias ediciones, empezando por su publicación conjunta con la obra de Juan Boscán y acabando con la edición de Azara (1765). Ofrece un comentario general de las diferentes ediciones y luego pone en relación unas con otras teniendo en cuenta la razón que gobierna cada una de ellas, fruto de los distintos contextos culturales. De corte más anecdótico, el artículo de Galbarro García "Garcilaso en cifras» se ocupa de uno de los manuscritos que formó parte de la biblioteca del VI Condestable de Castilla, Juan Fernández de Velasco (ca. 1550-1613). Se trata de una obra dedicada al Condestable que aparece registrada en el inventario con el título de Discursos de cifra y cosas curiosas de enigmas y cartas; un tratado anónimo de criptología constituido por dos partes: una primera en que se habla sobre la naturaleza y el uso de la cifra; y una segunda parte en que se aplica la teoría y se enseña a cifrar el contenido de las cartas utilizando los versos de varios poetas, entre los que se encuentra, por supuesto, Garcilaso. El investigador traza una breve historia de la cifra en Espańa y a continuación se ocupa de los versos del poeta, que son, por otro lado, los que más se utilizan en la segunda parte. El artículo "El mar de Camóes: camino y palestra» estudia desde un punto de vista tematológico la imagen del mar en la obra de Luis de Camóes, principalmente en la célebre Os lusíadas. Su autor, Antonio Carreira, la relaciona con varios episodios de la vida del escritor y con el fondo de determinados acontecimientos históricos; entre ellos, el que inspira la composición de $O s$ lusíadas, la primera expedición de Vasco da Gama. Insiste en que el mar, a diferencia de lo que será luego para el Romanticismo, «es [para Camóes], ante todo, un camino, el más peligroso» (p. 74); visión que se contrasta a veces, como refuerzo, con la de algunas crónicas marinas de la época.

Los dos artículos que siguen se centran en la obra de Fernando de Herrera. El primero, de Bienvenido Morros y de Irene Sebastián Perdices, estudia las relaciones entre los sonetos incluidos en Algunas obras (1582) que reaparecen más tarde en la versión definitiva de Versos (1619); en particular, el poema «Ardí, Fernando, en fuego claro y lento». Morros ya había estudiado dichas relaciones en un trabajo previo que le sirvió para plantear la hipótesis de que Fernando de Herrera, al punto de revisar su obra, había intentado borrar sus deudas con los poetas del petrarquismo, hecho que le llevó más tarde a reescribir algunos de sus poemas. ${ }^{2}$

2. Véase Bienvenido Morros, "Algunas observaciones sobre la poesía y la prosa de Herrera». El Crotalón. Anuario de Filología Española, II (1985), pp. 147-168. 
Para demostrarlo, vuelve otra vez sobre el soneto «Pensé, mas fue engañoso pensamiento", y, en efecto, después de valorar el tratamiento de algunas metáforas - especialmente, la del corazón helado- - y su relación con las distintas fuentes, se confirma dicha deuda y la voluntad por parte del poeta de querer enmendarla. Ahora bien, el soneto que nos presenta en esta ocasión viene a poner en entredicho tal hipótesis, lo que, en opinión de ambos autores, plantea la necesidad de un estudio sistemático. El segundo artículo "Siglo de Oro para las Anotaciones de Herrera» no se centra propiamente en la obra del sevillano, sino en el poema de Francisco Pacheco In Garci Lassi laudem genthliacon. Se trata de una oda latina, que abre los comentarios de la edición de Herrera y que, igual que la bucólica IV de Virgilio, utiliza el tópico del Siglo de Oro para anunciar la que se presenta como una edad próspera; en este caso, referida a las letras y vinculada al nacimiento de Garcilaso y al de los poetas que seguirán su estela. El autor José Solís de los Santos analiza las fuentes latinas y explica el origen y la evolución el tópico.

Las tres aportaciones que siguen se enmarcan en el estudio de la obra juvenil de Miguel de Cervantes y de Luis de Góngora. Respetando, como siempre, la propia ordenación del libro, la primera se titula «De la mujer-prisión a la mujer-templo (a propósito del soneto De pura honestidad templo sagrado)». Su autora Giulia Poggi hace una lectura de este conocido soneto de Góngora, el cual ha recibido interpretaciones muy variadas; para ello lo compara con la que se considera su fuente directa, el poema de Minturno "In sì bel tempio de memorie adorno", y con la canción de Petrarca, que a su vez sirvió de inspiración al soneto de Minturno, «Tacer non posso, et temo non adopre» ( $R V F$ 325). La investigadora subraya las diferencias entre la imagen empleada por los italianos, que conciben a la amada como una mujer-prisión, y la transfiguración literaria a la que la somete Góngora al utilizar la imagen de la mujer-templo. En opinión de la autora, se trata de un ejercicio por el cual el poeta cordobés consigue dar doble sentido sagrado y pagano a la imagen utilizada por Petrarca y Minturno. Es aquí donde vuelve sobre el poema de Bernardo Tasso "O d'intiera onestà tempio onorato", cuyo íncipit recuerda al soneto de Góngora. Tasso diviniza a la amada siguiendo el tópico de la religio amoris, y lo hace con una imagen, la de la mujer-templo, que tiene el antecedente en ámbito hispánico de los Sonetos fechos al itálico modo del marqués de Santillana; en particular del soneto VIII: «O dulce esguare, vida é honor mia, / segunda Elena, templo de beldat /...». Según Pozzi, el poema sería fruto de una relación intertextual compleja que, además de tener en cuenta el soneto de Minturno (y quizá también el de Petrarca), podría beber del soneto de Bernardo Tasso y/o del marqués de Santillana. Finalmente, explica que el contenido religioso, nacido a raíz de la comparación de la mujer con el templo, habría dado lugar a que el poema fuera censurado en la edición que Juan López de Vicuña hizo en 1628 de las obras de Góngora. De igual modo, el estudio de Antonio Gargano propone también una lectura del poeta; en este caso, del soneto "Con diferencia tal, con gracia tanta». El autor valora el grado de madurez poética y lo relaciona con su distanciamiento del petrarquismo y de la poesía de Garcilaso, la cual, como sabemos, influyó podero- 
samente en la obra juvenil de Góngora; para ello establece una comparación entre el poema del cordobés y sus antecedentes en Garcilaso (égloga I, vv. 324-340) y en la poesía de Petrarca ("Quel rossignuol che si soave piagne», $R V F C C C X I)$. Se trata de un trabajo que los especialistas Robert Jammes y, más recientemente, Orozco Díaz habían llevado a cabo con toda la obra juvenil del poeta: uno a finales de los ochenta y otro en el año 2002. Ahora bien, si el planteamiento de Jammes parte de que el poema se caracteriza por su deseo de rehuir una cierta concepción idealizante del amor, inherente al petrarquismo, para Díaz la novedad de este soneto, que lo acerca al manierismo y que constituye un paso decisivo en la evolución del estilo de Góngora, se basa en la complejidad estructural del poema, que reúne en varios niveles, bajo la figura del ruiseñor, el tema de la naturaleza, el del amor y el mito de Filomena. Esta es la línea en la que se encuentra el trabajo de Antonio Gargano. A la lectura de Díaz y de los distintos niveles temáticos, y para demostrar que es cierta su afirmación sobre el grado de complejidad del poema, el investigador añade un cuarto nivel temático: este podría ser leído como una relación en términos forenses del crimen cometido sobre Filomena: «A partir del "atroz hecho" del que es víctima la muchacha por obra de su cuñado Tereo, el mito de Filomela-ruiseńor resulta trasladado en los términos de pleito o causa, gracias a la ambigüedad de algunas locuciones que, junto con el significado pertinente respecto al contexto del relato mitológico, asumen el valor de expresiones jurídicas» (p. 136). De este modo, se estaría superando doblemente el modelo del petrarquismo: en primer lugar, a través de un lenguaje conceptuoso, que se volvería característico del estilo de Góngora; y en segundo lugar, y como consecuencia, por el papel desempeñado por la figura del ruiseñor. A diferencia de lo que ocurre en Petrarca y en Garcilaso, que confunden tradicionalmente su imagen con la del poeta, Góngora expresa su deseo de ruptura disociándola de la voz poética e identificándola con la protagonista del relato mitológico. La última de las tres aportaciones, escrita por Francisco Rico, se ocupa ya de la figura de Cervantes y en particular de su relación con Antonio Veneziano, el también escritor y amigo del alcalaíno, autor de un cancionero petrarquista escrito en dialecto siciliano. La obra poética de Veneziano se incluye en un manuscrito de la Biblioteca centrale della Regione siciliana. Dicho manuscrito presenta la peculiaridad de que contiene en una primera parte la poesía de Veneziano y, en una segunda, a modo de epílogo, unas cuantas composiciones de Cervantes. Se trata de una carta que envía a su amigo el 6 de noviembre de 1579 junto con doce octavas reales, también suyas, y un soneto de agradecimiento. Llama poderosamente la atención del profesor Rico, además del hecho de que el manuscrito está escrito a dos manos, una para la obra de cada escritor, que la mano que transcribe las obras de Cervantes utiliza una grafía sospechosamente parecida a la suya. Por este motivo, para descartar que no se trata de la letra de Cervantes, Rico la compara con otra carta que el autor del Quijote envía por las mismas fechas al secretario del Consejo de Indias Antonio de Eraso. El resultado del cotejo le permite observar que efectivamente no se trata de la letra de Cervantes. Ahora bien, el parecido entre las dos grafías le lleva a formular la hipótesis de que el copista que transcribió las obras lo 
hizo basándose en los autógrafos de Cervantes, lo que, en última instancia, explica que imitara su manera de escribir. Por último, destaca también el hecho de que, en una de estas octavas, se halla ya el principio poético cervantino, enunciado en uno de los tercetos del Viaje del Parnaso, «mostrar con propiedad un desatino»; en concreto, en la octava VII.

A partir de aquí completan este segundo bloque toda una serie de trabajos que comienzan con la poesía del conde de Salinas y que acaban con la obra de Enrique Vaca de Alfaro. Se trata de artículos, como siempre, centrados en aspectos muy concretos y en cuya totalidad abarcan un conjunto temporal amplio que va desde finales del siglo Xvi hasta llegar al Barroco tardío. El primero se titula «Entre el amor y el conocimiento: algunas consideraciones sobre la poesía del conde de Salinas»; en él Guillermo Serés analiza algunos de los motivos que se desprenden del tema central de la obra del conde: el conflicto entre el amor y el conocimiento. Para ello, traza un recorrido de la historia amorosa narrada por el poemario y utiliza los distintos motivos para ejemplificar literariamente algunas de las contradicciones que se derivan de dicho conflicto; motivos como los celos, el deseo y la imposibilidad de mitigar tales sentimientos con la representación mental del ser amado. El siguiente artículo, de Aurora Egido, tiene por objeto el célebre poema «A la salida de la cárcel» de Fray Luis de León. A diferencia de lo que ocurre con otras lecturas que se han hecho del poema, las cuales parten de las circunstancias específicas en que fue escrito, Egido intenta darle un sentido universal que lo vincula a otras composiciones del poeta. La autora parte del hecho de que no está claro que Fray Luis lo escribiera estando en la cárcel o a la salida de esta, según rezan los títulos de algunas de sus versiones. Para Egido, la cárcel de la que habla Fray Luis, si bien podría designar la cárcel física en que estuvo preso, tendría también el significado de la cárcel corporal de la que el poeta quiso siempre liberarse; cárcel que, en última instancia, vendría referida a la materialidad, origen de la envidia y de la mentira en el mundo. La estudiosa lo relaciona con otras composiciones suyas que expresan este deseo empleando la misma imagen y también con la posición que ocupa el poema en el interior del poemario de Fray Luis. Su contenido moral de inspiración clásica y agustiniana, en opinión de Egido, explicaría que se encontrara al final del primer libro y como punto de engarce con los libros segundo y tercero, los cuales se sitúan ideológicamente también en esas coordenadas. Finalmente, por el lado de la forma, llama la atención sobre el hecho de que el poema utilice un lenguaje llano y una métrica sencilla, las quintillas dobles, para expresar altos conceptos que vienen de la filosofía moral. Para Egido, sería una muestra más de la humildad expresada en la segunda estrofa y en general del carácter epigramático del poema, ese multum in parvo que encabeza el título del trabajo y que en la obra de Fray Luis viene a condensar en diez versos toda una filosofía. El artículo de Francisco Javier Escobar y de Juan Montero está escrito a propósito de la canción que el poeta Francisco de Medrano dirige a Felipe II durante su visita al Colegio Ânglico de Valladolid el 3 de agosto de 1592: «En aquestas paredes derribadas / reluce tu piedad, Filipo augusto (...)». Ambos autores llevan a cabo un estudio de las variantes entre los 
distintos testimonios que se conservan de este poema y a partir de ahí proponen algunas consideraciones relativas a su proceso de composición; a saber, que la canción está escrita en tres fases redaccionales las cuales tienden paradójicamente a fortalecer la presencia del poema que les sirve de inspiración: la canción de Bartolomé Leonardo de Argensola «A la nave de la Iglesia». Ante este hecho en apariencia contradictorio, ya que lo lógico sería suponer lo contrario, la explicación que encuentran los dos investigadores se basa en el concepto que Medrano tenía de su poema. Al autor no le habría importado acrecentar su deuda con el modelo, entre otras cosas porque justamente se trataba de un ejercicio de imitación que habría iniciado en 1592 durante sus años de aprendizaje como poeta. El artículo de Luis Gómez Canseco «Dos odas de Horacio traducidas por Mateo Alemán» vuelve otra vez sobre la figura de Fray Luis de León con motivo de sus traducciones de las odas 10 y 14 del segundo libro de odas de Horacio. El autor las compara con las llevadas a cabo por Mateo Alemán durante sus años de juventud y llega a la conclusión de que el escritor sevillano no solo imitó su modo de traducir, sino que en algunos casos tomó incluso su misma traducción. Por último, incluye en aparato crítico las variantes de las distintas traducciones. En «Nuevos datos sobre el final de la estancia de Lope en Sevilla» se nos habla de uno de los pocos episodios desconocidos de la vida de Lope. Hay un vacío biográfico en el momento en que el poeta abandona Toledo y se instala durante un tiempo en Sevilla. Tal episodio ha dado a lugar a múltiples conjeturas basadas en el hecho de que se sabe que estuvo allí en 1602, pero no cuándo llegó, cuándo se fue ni tampoco los periodos en los que residió allí. José Manuel Rico García, el autor de este trabajo, ofrece un documento inédito que permite asegurar la presencia del poeta en Sevilla desde 1602 hasta julio de 1604 .

Los dos artículos que siguen vuelven otra vez sobre la figura de Miguel de Cervantes, aunque el contenido en este caso se enmarca en su periodo de madurez. El primero, de Víctor Infantes, estudia la producción poética de la literatura de cordel durante el bienio cervantino 1604-1605; es decir, en el momento previo a la publicación de la primera parte del Quijote. Infantes plantea la posibilidad de que el escritor alcalaíno se sirviera de esta clase de textos para utilizarlos en algunas de sus obras, ya que se trataba de textos que, a pesar de tener una ínfima calidad literaria, constituían un auténtico fenómeno social y comercial de la época. Empieza haciendo un repaso de los distintos tipos de pliegos y luego registra y describe el número de pliegos que se conservan de dicho periodo: un total de «19 míseros pliegos» que, en opinión del autor, es una «rácana cosecha de la que de verdad debió de ver la luz» (p. 213). Infantes dice que no hay constancia de que el novelista leyera estas obras, pero sí de que las conociera, y es aquí donde añade algunos ejemplos que vendrían a confirmar tal hipótesis. El segundo artículo está escrito por el profesor Alberto Blecua y se titula «Lectores y plumas en Cervantes». El autor se centra en algunas de las referencias literarias que aparecen en la obra del genio alcalaíno y las comenta a propósito de los gustos del escritor y también de algunos de sus personajes. El objetivo es intentar dar una visión panorámica de las 
preferencias literarias de la época y de aquellos elementos de la obra de Cervantes que, en cierto modo, anticipan o se hallan en la vanguardia de determinados géneros literarios como, por ejemplo, la novela policiaca.

El siguiente grupo de trabajos se relaciona con la obra de los autores cultos. El primero de ellos está escrito por Alejandro Gómez Camacho; contrasta con los demás artículos que integran este volumen porque se interesa por el tema lingüístico y no el literario, como sucede en el caso de los anteriores. Camacho estudia el tema de la enseñanza de la ortografía en España durante el siglo Xviı y lo hace con motivo de la obra de Juan de Robles. El autor traza un breve recorrido de su historia hasta llegar a la publicación de El culto sevillano (1631); a partir de ahí, lleva a cabo una descripción general del contenido del libro y explica su relación con las principales corrientes ortográficas de la época, en especial con las que siguen el modelo de escritura fonética planteado por Fernando de Herrera en sus Anotaciones a la poesía de Garcilaso. El artículo de Melchora Romanos «Reescrituras y lecturas del Polifemo de Góngora», a diferencia de los que ya vimos de Antonio Gargano y de Giulia Poggi, se ocupa de la figura de Góngora durante sus años de madurez. Romanos plantea algunas observaciones centradas en las distintas lecturas que ha recibido el poema desde el momento de su publicación en 1612. Empieza haciendo referencia a su valoración en el contexto de las polémicas gongorinas y luego conecta este discurso con el trabajo de profundización en la obra del cordobés - y, por ende, en dichas polémicas - que llevaron a cabo, a comienzos del siglo xx, Dámaso Alonso y Jorge Guillén. La autora se centra en particular en la tesis doctoral del poeta de Valladolid, sus Notas para una edición comentada de Góngora: pone de relieve cómo Jorge Guillén rescata para su comentario no solo las páginas de los comentaristas impresos (Pellicer y Salcedo Coronel), sino también las anotaciones manuscritas de Pedro Díaz de Rivas y de Andrés Cuesta, de las cuales Romanos había hablado en la primera parte; finalmente, subraya el desconocimiento que se tenía entonces de estas obras y del importante trabajo desempeñado a este respecto por la generación del 27. El artículo ya citado de Nadine Ly «Aimez ce que jamais on ne verra deux fois: Góngora: entre repetición y hápax» propone, según vimos más arriba, una definición del término hápax que tiene en cuenta su uso retórico. La autora plantea la hipótesis de que el escritor cordobés lo utiliza como recurso literario a partir de la percepción estética que de tal uso hicieron los poetas épicos de la Antigüedad; completa este trabajo con un breve muestrario de las palabras que Góngora emplea una sola vez y reclama, en ese sentido, la necesidad de un estudio sistemático que abarque toda la obra completa. Por su parte, el estudio de Juan Manuel Daza Samoano vuelve otra vez sobre el tema de las polémicas gongorinas, en este caso a propósito de las autoridades que sirvieron para la defensa del escritor cordobés. El autor explica que muchas de ellas, entonces consideradas no canónicas, fueron utilizadas en los distintos tratados no con un simple criterio cuantitativo - aumentar el número de las autoridades empleadas-, sino como un intento de justificar teóricamente algunos de los desmanes o excesos que, desde un punto de vista ortodoxo, trajo consigo la poesía de Góngora. Samoano pone el 
ejemplo de las paráfrasis de Longino utilizadas por Pedro de Valencia, pero se centra sobre todo en las Anotaciones y defensas a la primera «Soledad» escritas por Pedro de Rivas. El investigador señala las autoridades que se hallan detrás de los postulados estéticos con los que Rivas defiende a Góngora; principalmente sus puntos en común con las teorías expuestas por Fracastoro en el Naugerius, sive de Poetica dialogus (1555). El artículo que completa esta serie dedicada a los autores cultos está escrito por Iván García Jiménez y lleva por título "'Aunque un tiempo competimos...". Apostillas a la rivalidad entre Salcedo y Pellicer». El estudio aborda la polémica habida entre los dos editores con motivo de la publicación del Polifemo comentado (1629). La edición del poema que llevó a cabo Salcedo Coronel le arrebató a José Pellicer y a sus Lecciones solemnes (1630) el privilegio de ser el primer comentarista y comentario impreso de las obras de Góngora. De este hecho, nació una rivalidad entre los dos editores que habría de prolongarse durante el tiempo y de la que García Jiménez viene a hablarnos en este caso. Se trata de un tema ya estudiado por Dámaso Alonso, pero sobre el que el investigador vuelve con tal de aportar nuevos detalles y sobre todo de profundizar en la que finalmente devino amistosa relación. Es en este último punto que García Jiménez aduce varios testimonios y algunos datos biográficos interesantes con relación a este propósito.

Los dos artículos que siguen, de Lía Schwartz y de Sagrario López Poza, se ocupan de la figura de Quevedo. Empezando por el primero, «Principios de la ética estoica en textos de Rioja y Quevedo: dos voces poéticas en contrapunto", tal y como anuncia el título analiza los parecidos y diferencias en la representación literaria de los principios de la ética estoica en ambos autores; lo hace a propósito de las dos traducciones del Encheiridion de Epicteto: la llevada a cabo por el Brocense y la que Quevedo escribe en verso a imitación de la anterior. Schwartz compara las dos traducciones para ver en qué puntos se aleja Quevedo de la lección de Epicteto, y es entonces, tras definir su visión del pensamiento estoico, que la contrasta con la que ofrecen los poemas de Rioja. A diferencia del anterior, que se ocupa del contenido, el artículo de López Poza aborda la obra de Quevedo desde el punto de vista de los géneros literarios, en particular, del epigrama. La autora formula una definición del concepto, según los parámetros genéricos del Siglo de Oro, con idea de identificar, en primer lugar, qué creaciones de Quevedo merecen este apelativo y, en segundo lugar, cuál es su particular realización del género y en qué se distingue de los otros epigramas de la época. A partir de ahí, establece una tipología de los epigramas y hace una valoración de los resultados obtenidos.

El último grupo de artículos, que completa este segundo bloque, se centra en figuras más o menos conocidas nacidas ya en el siglo XVII. El primero se titula «Poética cultista y canon áureo en la poesía contemporánea española. Una nota sobre Bocángel y los novísimos». El estudio se interesa por la presencia de los autores cultos - en especial, de Gabriel Bocángel — en la obra de los llamados poetas novísimos; relaciona la voluntad rupturista de esta generación con la que se apreciaba ya en el siglo XVII entre los epígonos de Góngora. Empieza con un breve recorrido histórico de la recepción de la obra del cordobés, con su consabida omisión entre 
los autores ilustrados y la no menos conocida revalorización que trajeron los poetas del 27. Es dentro de este nuevo interés por la poética cultista donde Javier Âlvarez e Ignacio García Aguilar, los autores de este trabajo, sitúan, en última instancia, la recuperación y actualización de la obra de Bocángel y su influencia en la poesía de Leopoldo María Panero, Pere Gimferrer y más particularmente en la obra de Guillermo Carnero Dibujo de la muerte (1967). El artículo de Mercedes Blanco «Paradojas, agudeza y ciencia en Baltasar Gracián» está escrito a propósito de las supuestas contradicciones que caracterizan el tratado Agudeza y arte de ingenio (1648). Se propone demostrar que tales contradicciones no se deben a la «incapacidad teórica por parte de su autor», sino a la misma «naturaleza del concepto agudo» (p. 348). Blanco hace un repaso del contenido general de la obra, haciendo hincapié en las definiciones de "concepto» $y$ «agudeza», para demostrar que el problema no son las incoherencias, sino la densidad del lenguaje de Baltasar Gracián, que da lugar a una estructura desordenada del libro — «la ausencia del orden sistemático y deductivo que nos esperaríamos en la exposición didáctica de un "arte" o "ciencia"” (p. 352)_ y exige la participación de un lector activo que resuelva cuanto hay implícito en él. Trae también a colación a este respecto algunas de las diferencias que hace el escritor entre ciencia e ingenio, sus ideas en torno a la verdad y el arte, los tipos de agudeza $y$, en suma, todos aquellos aspectos que sirven para mostrar que dichas incoherencias son solo aparentes y deliberadas. El trabajo colectivo de Elena Cano Turrión, Almudena Marín Cobos, Ana Isabel Martín Puya y Pedro Ruiz Pérez, titulado "Concepto, devoción y rimas: las Décimas a la Inmaculada concepción de nuestra señora (Granada, 1650)», gira en torno a la polémica teológica sobre la Purísima concepción de la Virgen; polémica que tuvo lugar en España a lo largo del siglo XVII y que enfrentó ideológicamente a una parte del pueblo español, la de los llamados inmaculistas, con aquella otra, la de los maculistas, que no creía en la concepción libre de pecado. Fruto de este enfrentamiento fueron la publicación de una serie de pliegos que contenían poesías a favor o en contra y que eran utilizados generalmente como carteles poéticos a modo de propaganda. Los autores del artículo toman el ejemplo de un pliego publicado en Granada en 1650. Dicho pliego contiene unas décimas que permiten conocer en el ámbito local algunos aspectos de este debate. El estudio profundiza sobre estos aspectos y también sobre su relación con la forma métrica empleada para los poemas. El siguiente artículo, de María José Osuna Cabezas e Inmaculada Osuna Rodríguez, edita dos romances escritos respectivamente por el poeta Fernando de la Torre Farfán y la también poetisa Catalina Clara Ramírez de Guzmán. Está dividido en dos partes: una primera en la que se nos explica el contexto que da lugar a los dos romances; y una segunda, a modo de anejo, en la que se incluyen los poemas con las notas. Dentro de la primera parte, se explica que los poemas son en realidad una réplica y contrarréplica que los dos escritores se hacen con motivo de una comedia, hoy desconocida, que la escritora iba a presentar en un certamen poético en el que Farfán acudía como fiscal, pero que al final fue rechazada precisamente por la intervención de este último, que valoró negativamente la comedia de Ramírez de Guzmán. Las dos autoras aportan algunos detalles más 
sobre dicha polémica recalcando también el hecho de que los poemas demuestran el crédito literario que Farfán tenía ya en 1653, una década antes del periodo que suele atribuírsele. El artículo de Cipriano López es otro ejemplo de poesía mural en el siglo XVII, en este caso de poesía mural fúnebre. El autor da la noticia de un poema escrito por Francisco de Godoy a propósito de la muerte del arzobispo de Sevilla Ambrosio Ignacio Spínola y Guzmán; poema que no se incluye en los repertorios bibliográficos. Se trata de un soneto que tiene por título «En la temprana, / y lastimosa mverte, / del Illmo. y Rmo. señor / D. Ambrosio Ignacio / Spinola y Guzmán», el cual «fue impreso en folio, a una sola cara y con el único adorno de una orla tipográfica» (p. 414). El autor relaciona las características del formato en que se conserva el poema con las que Simón Díaz atribuyó en los años 70 al poema mural, y es apoyándose en esta autoridad que explica que el soneto habría servido de adorno al túmulo funerario del arzobispo. Su aportación, por lo tanto, es doble, ya que, por un lado, engrosa el número de obras conocidas de este poeta prácticamente desconocido, y por el otro, hace otro tanto con el corpus poético de poesía mural. Por último, el artículo que cierra la serie está escrito por María Ángel Garrido Berlanga y se centra en la obra poética del médico cordobés Enrique Vaca de Alfaro; aborda, en particular, dos poemas suyos que se localizan en un impreso poco conocido de la época: la obra del franciscano Padrique del Monte La Montaña de los Ángeles (1674). Se trata de dos poemas que tiene además el interés de que son los dos únicos sonetos laudatorios de Vaca de Alfaro que se encuentran en una obra ajena. La autora analiza el contenido de los dos sonetos en relación con el contexto de la obra de Padrique del Monte y de la finalidad autopromocional con que los concibió Vaca de Alfaro.

Para acabar, hay un tercer bloque, que viene a despedir el volumen, el cual, a diferencia de los dos anteriores, cuenta solo con las aportaciones de Ángel Estévez Molinero y de Isabel Román Gutiérrez. Se trata de dos artículos que abordan el tema de la conformación del canon de la poesía áurea y en general su recepción en los siglos XVIII y XIX. La primera se titula «Prensa y márgenes historiográficos: unas notas sobre el Siglo de Oro de la poesía»; reflexiona sobre el concepto Siglo de Oro y sobre cómo ha intervenido en su difusión la publicación de textos que no pertenecen estrictamente al ámbito historiográfico. Se trata de las publicaciones periódicas. Estévez se ocupa una de ellas, El cajón de Sastre Catalán; la compara con dos textos que sí pertenecen a dicho ámbito: los Orígenes de la poesía castellana (1754) de Luis José Velázquez y el Parnaso español (1768-1778) de Juan José López de Sedano. El estudio pone de manifiesto que, a pesar de basarse en los criterios clasicistas que utilizan ambos autores, el Cajón de Sastre Catalán hace una selección mucho menos rígida, que desplaza paradójicamente la periodización de lo que López de Sedano y Luis José Velázquez consideran que es el Siglo de Oro. Por su parte, el trabajo de Isabel Román se traslada ya al siglo xIx. La autora estudia la figura del poeta Narciso Campillo en su faceta de preceptista y más particularmente el segundo volumen de su obra Florilegio español (1885). Su aportación conecta con el anterior artículo en tanto en cuanto se trata de una obra que es una muestra 
de la pervivencia del clasicismo aunque inmerso ya en el contexto romántico. La única diferencia entre la obra de Campillo y la que acabamos de ver de Luis José Velázquez y de Juan José López de Sedano - y de ahí su novedad con respecto a los anteriores - es que el poeta sevillano, por su condición misma de poeta y por el hecho de estar haciendo historia literaria, hace todos los esfuerzos posibles por intentar llevar el agua a su molino. La jerarquía de autores que establece Campillo da clara prioridad a los poetas de la Escuela de Sevilla, en particular a la obra de Francisco de Rioja, de la que él se siente una especie de heredero espiritual; así, en este doble juego entre pasado y presente, asegura también su futuro como poeta.

López Bueno, Begoña (ed.)

Entre sombras y luces. La recepción de la poesía del Siglo de Oro de 1700 a 1850 Sevilla, Universidad de Sevilla, 2014, 362 p. Literatura; 136.

ISBN 978-84-472-1595-9

Vale la pena terminar con los trabajos de Estévez Molinero y de Isabel Román no solo porque, en efecto, son los que concluyen el libro, sino porque muestran también cómo el contenido del primer volumen, al ser un reflejo de las dos principales etapas que caracterizan la trayectoria del grupo PASO, anticipa a su vez la temática del segundo volumen, el cual se titula justamente Entre sombras y luces. La recepción de la poesía del Siglo de Oro de 1700 a 1850 (2014).

Se trata de la última de una serie de publicaciones, editadas bajo la dirección de Begońa López, las cuales son el resultado de varios Encuentros Internacionales que se celebraron entre 2003 y 2008. Todas se interesan por la historia de la recepción de la poesía áurea en sus distintos momentos históricos, empezando por la de los propios poetas. La primera de ellas, En torno al canon aproximaciones y estrategias (2005), sentó las bases de las que constituirían las dos publicaciones siguientes, además de la ya señalada: El canon poético en el siglo XVI (2008) y El canon poético en el siglo XVII (2010). Con ellas, el grupo PASO quiso sumarse a toda una serie de estudios de tipo historiográfico que se venían publicando con tal de iluminar determinadas zonas de la historia de la recepción literaria.

Es en este contexto que encontramos también la publicación del volumen Entre sombras y luces. Este se ubica en uno de los periodos más fértiles de la historiografía literaria, como son los siglos XVIII y XIX: en primer lugar, por el desconocimiento todavía existente sobre dicho periodo, en especial del Barroco tardío y de la llamada generación de los novatores; y, en segundo lugar, porque es propiamente durante este intervalo de tiempo cuando se organiza la institución literaria, con la conformación del canon lírico áureo. Así pues, el presente volumen viene a cubrir estas dos necesidades mediante una colección de artículos que no solo se interesa por el panorama historiográfico, sino que atiende también puntualmente a la producción poética del periodo. 
El volumen, igual que el homenaje a López Bueno, sigue una ordenación cronológico-temática que da lugar a los siguientes apartados. Hay un primer bloque teórico, constituido por los trabajos de Inmaculada Urzainqui y de José Checa, que introduce el volumen dando una visión panorámica de las obras que se incluyen en el periodo estudiado y de las variaciones que se producen en el pensamiento crítico a lo largo del siglo xviII. Este apartado enmarca el contenido de las contribuciones que forman el grueso del libro, las cuales se centran en aspectos concretos de algunas de las obras que se mencionan en el primer apartado. Se trata básicamente de textos historiográficos, escolares y también de publicaciones periódicas. Todas estas contribuciones se ordenan según el año y también el lugar de publicación de dichas obras. Así, los primeros artículos de este segundo bloque abordan textos que se publican dentro del panorama español, mientras que los tres últimos se centran en las obras publicadas en el extranjero.

Empezando por los estudios de Inmaculada Urzainqui y de José Checa, el primero, como se ha dicho, es un texto teórico que ofrece una mirada general del panorama historiográfico español durante el Setecientos y los primeros años del Ochocientos. La autora hace algunas valoraciones acerca de lo que significó para la historiografía literaria las propuestas de los autores ilustrados; el hecho de que sirvieron para reforzar la identidad nacional y atraer también las ideas ilustradas de buen gusto y racionalidad, pero sobre todo subrayando el grado de exigencia y de rigurosidad que las distinguieron de otras propuestas anteriores. En palabras de Urzainqui, es a partir del siglo XVIII «cuando la literatura entra en la historia y se hace objeto de análisis y reflexión desde una perspectiva histórica» (p. 17). Fue la necesidad de comprender un presente que consideraban de decadencia lo que llevó a los autores ilustrados a intentar darle un sentido a la historia literaria que sirviera a su vez para determinar cómo había de ser su futuro. En ese sentido, la autora destaca el carácter pedagógico que significó para la poesía dicha revisión histórica, que además sirvió para que se multiplicasen los estudios literarios, las bio-bibliografías y las ediciones y reimpresiones de los autores españoles.

Tras estas consideraciones generales, que servirían también para cualquiera de los trabajos reseñados en el presente volumen, Urzainqui repasa las principales obras del periodo que poseen algún interés para la historiografía literaria. Se trata de textos que presentan "formas muy diversas de contar la literatura» (p. 19) según la importancia de esos tres elementos que acabamos de ver que caracterizan el periodo; a saber, la voluntad de escribir una historia de la literatura, de reforzar la identidad nacional y de hacer pedagogía. La distinta configuración de esta serie de elementos hace que las obras se distingan por el formato en que se presentan: poéticas, libros de historia, publicaciones periódicas, etc.

Urzainqui hace un catálogo de las distintas obras para luego centrarse en tres de ellas. Esta constituye, a diferencia de la primera parte, la parte concreta del estudio, que nos lleva de la teoría a la práctica para conocer por de dentro algunas de las variaciones que se producen en el pensamiento crítico durante el siglo. La autora escoge para ello tres obras muy emblemáticas, como son los Origenes de la poesía 
castellana (1754) de Luis José Velázquez, la obra de Francisco Javier Lampillas Ensayo histórico-apologético de la literatura española (1782-86) y el tratado de José Andrés Dellorigine, progressi e stato attuale d'ogni letteratura (1782-1799). Urzainqui describe las tres obras en función del propósito y del contexto en que se gestaron y analiza sus parecidos y diferencias. En ese sentido, constata que, a pesar del gusto neoclásico que es común a ellas - y que lleva en el caso de Velázquez a hablar de una edad de oro de la literatura que habría sido solo el siglo xvı-, la comparación de una con otra muestra una progresiva asimilación en el canon lírico áureo de autores que forman parte del periodo de entre siglos (Quevedo, Góngora, Lope).

El segundo artículo, de José Checa Beltrán, «Recepción de los modelos líricos áureos en el siglo ilustrado», complementa el trabajo de Inmaculada Urzainqui en tanto en cuanto recupera su idea de las variaciones que se producen a lo largo del siglo, pero no a partir de un acercamiento a los textos, como sucede en el caso del anterior, sino a través de un enfoque general que se sirve de un método puramente especulativo. Por ello, empieza el artículo con un apartado de "presupuestos" teóricos en el que intenta, además de referir las tales variaciones, clasificarlas según las distintas etapas que habrían caracterizado el debate historiográfico dieciochesco. El autor parte de dos momentos históricos que habrían llevado el debate a su máximo apogeo: uno, en el primer cuarto de siglo, con la publicación de la obra de Mayans, Luzán, el Diario de los literarios y, en suma, de los demás miembros de la llamada Academia del Buen Gusto; y un segundo momento histórico, a finales de siglo, en el que las discusiones historiográficas habrían evolucionado hacia los postulados de la poesía filosófica. Checa los relaciona con la situación política de España y su relación con el resto de Europa, en especial con Francia, que era su nuevo centro cultural y artístico. Partiendo de estas ideas estéticas y políticas el autor fragmenta el pensamiento crítico del siglo en tres periodos:

El primero empieza en 1730. La introducción de ideas extranjeras habría supuesto una contienda entre los autores más tradicionalistas $-\mathrm{O}$, si se quiere, más castizos - con aquellos otros que ya hemos mencionado que integraban la Academia del Buen Gusto. A pesar de que no se trataba de ideas nuevas, ya que estaban presentes durante el Renacimiento, se percibían de esta manera por el hecho de formar parte del gusto francés, el cual las había puesto de moda.

El segundo momento que distingue Checa se produce en 1750. En este punto, la situación política del país, con la entrada de los borbones y de su voluntad reformista, hace que los autores neoclásicos ingresen en las instituciones e impongan desde allí sus ideas estéticas. Esto, unido a la imagen política y cultural denigrante que se proyecta de España en el extranjero, fuerza a que el debate historiográfico entre castizos y neoclásicos se centre cada vez más en su aspecto nacionalista, con obras que aceptan progresivamente autores que, durante el primer cuarto de siglo, no entraban a formar parte del canon lírico áureo.

Plenamente asentada la ideología política y cultural de los autores ilustrados, el último cambio que se percibe en la poética del siglo tiene lugar, según Checa, a finales de 1780. Coincide con este hecho el cambio del clima político que se 
produce en Francia a raíz de la Revolución, el cual tiene como consecuencia en el ámbito cultural una pérdida total de la hegemonía del clasicismo y una apuesta mayor por el relativismo y la revalorización nacional. Esta nueva tesitura confirma la tendencia historiográfica que habíamos visto, y son cada vez más los autores del Barroco los que entran a formar parte del canon de los poetas líricos. Esto, en el ámbito de la historiografía. En términos de producción poética, el autor atisba un progresivo interés por la llamada poesía filosófica, que, a diferencia de la neoclásica, justamente porque intenta estar a la altura del momento histórico, deja a un lado la importancia de la forma y se interesa cada vez más por el contenido.

A partir de aquí, como se señaló más arriba, los demás artículos que integran el volumen se detienen a estudiar algún aspecto concreto de los textos mencionados en los dos anteriores; de tal modo, que sus presupuestos teóricos son válidos para los siguientes. El primer artículo, que abre este segundo bloque, está escrito por Juan Montero y se titula "Flores del Parnaso: la recepción de la lírica áurea en dos códices de la primera mitad del XVII». La obra en cuestión es una antología poética que el investigador analiza, en una primera parte, con relación a las expectativas generadas por el título: las flores «escogidas de nuestros mejores poetas y de algunas cuyas obras no se han impreso", lo cual resulta, a la postre, falso en tanto que conviven poetas de verdad relevantes con otros que formarían parte de una segunda fila. Y lo mismo cabe decir de la afirmación «cuyas obras no se han impreso». Después de hacer una descripción general del contenido del manuscrito y de desmentir las expectativas creadas, Montero lo compara con otro códice perteneciente a la Biblioteca de la Fundación Bartolomé March con el cual parece haber una filiación genética. Se trata del Ramillete de Flores de el Parnaso, de algunos de los celebràdos Ingenios de España, que no se hallan impresas. El autor compara los dos manuscritos desde el punto de vista de la composición, la estructura y también de la relación textual. El estudio de Pedro Ruiz Pérez «Siglo de Oro y canon moderno: Benegasi contra Velázquez» se enmarca dentro de aquella segunda fase en la que José Beltrán Checa situaba la reacción nacionalista a la imposición de las ideas estéticas neoclásicas. Por ello, el propio autor empieza haciendo un repaso de dicho periodo para centrarse luego en las polémicas nacidas en el presente con motivo de las distintas maneras con la que los autores ilustrados seleccionan y canonizan a los poetas del pasado y del presente. En su caso, Ruiz Pérez aborda la obra de José Joaquín Benegasi y Luján Panegírico de muchos, envidiados de no pocos (1755). El autor intenta demostrar que supuso una contestación a los Origenes de la poesía castellana, que se habían publicado un año antes y que dejaban a Benegasi fuera del canon de poetas contemporáneos. Pérez relaciona este hecho con la propia selección de autores que hace Benegasi, la cual compara con el canon de Velázquez. El resultado de esta comparación es que si para Velázquez hay un Siglo de Oro, que es el xvi, y luego un periodo decadencia, que abarca todo el Barroco, en el caso de Benegasi no hay fractura. El autor, con tal de justificar su obra y la de los demás poetas de su tiempo, mantiene una continuidad con el Barroco que conecta directamente con la obra de los contemporáneos. Para ello, a diferencia de 
Velázquez — y en opinión de Ruiz Pérez, por no hacerle una concesión—, no solo no utiliza el término Siglo de Oro, que el otro emplea por primera vez en la historia literaria, sino que omite también en la selección de los autores algunos que, según Velázquez, entrarían a formar parte de este periodo. Por el contrario, las partes que silencia Velázquez son aquellas a las que da voz Benegasi y viceversa. El poeta madrileño mantiene una postura ecléctica que le lleva a intentar cuadrar, dentro de los postulados neoclásicos y en sintonía con los gustos del público, la obra de los poetas de su tiempo, que sigue la tradición bajo barroca. Es en ese sentido que finalmente Ruiz Pérez vuelve otra vez al principio para hacer una reflexión acerca de lo que significó el Neoclasicismo para España, el cual se impuso no sin problemas: «Antes bien, el que acabaría imponiéndose como el canon neoclásico e ilustrado encuentra no pocos contrapuntos y oposiciones, y entre ellos cabe situar la propuesta de Benegasi» (p. 149). El artículo de Ana Isabel Martín Puya, «El Garcilaso de Carlos III: ideas poéticas de Azara», estudia la recepción y canonización de Garcilaso en el siglo XviII a partir de las ediciones que se llevaron a cabo, en particular la edición de Azara. Igual que en el trabajo de José Checa, la autora une el gusto literario a una determinada situación política del país en la que los neoclásicos ocupaban ya la centralidad política, emanada del poder real; lo relaciona con el contexto en que se gestó la edición de Azara, durante el reinado de Carlos III y su proyecto de reformas. Martín Puya sostiene que algunos de los presupuestos que defiende la edición, la idea de lengua, patria y ciencias, solo se entienden dentro del marco de ese proyecto de reformas culturales que llevaron a cabo los ministros de Carlos III con tal de recuperar una tradición nacional que sirviera de escudo para las críticas extranjeras: «El siglo XviII viene marcado culturalmente por el proyecto de recuperación de una tradición nacional que posibilite la defensa ante las críticas extranjeras y el resurgir de las artes y letras contemporáneas. El epicentro de este programa lo hallamos durante el reinado de Carlos III; no obstante, desde comienzos de siglo encontramos una tendencia que apunta en esta dirección» (p. 178). Por su parte, el estudio de Begońa López Bueno «Algunas curiosidades en torno a la recepción de los grandes (Garcilaso, Herrera, Góngora)" pone de relieve parte de las contradicciones que hemos estado viendo hasta ahora a propósito de las relaciones entre el Neoclasicismo con los sectores más tradicionales. Empieza justamente con unas reflexiones acerca del canon dieciochesco y de los prejuicios de antibarroquismo y patriotismo con los que nació para explicar algunos aspectos acerca de la constitución del mismo y en particular su componente de ruptura con la tradición más inmediata. Dentro de este clima sitúa la recepción de los tres poetas que se mencionan en el título atendiendo a aquellos detalles que resultan curiosos - y en algunos casos incluso paradójicos- con relación a su posición dentro del canon establecido durante el periodo estudiado; por ejemplo, la contradicción entre la preeminencia que parece tener Garcilaso y, sin embargo, su escasa presencia en las antologías poéticas: López Bueno la compara con la que tiene Góngora a pesar de ser uno de los autores desterrados por el Neoclasicismo. 
Hasta aquí los textos abordados por este segundo bloque eran de naturaleza puramente historiográfica: la edición de Garcilaso de José Nicolás de Azara, los Orígenes de la poesía castellana de Luis José Velázquez... Los siguientes artículos abordan el tema de la recepción literaria pero vista desde los márgenes de la historiografía, en textos que no pertenecen estrictamente a este ámbito, sino al de la prensa periódica y al de los textos escolares. Se confirma la tendencia que habíamos visto con los anteriores. En algunos casos, como el de Benegasi, éramos testigos de cómo terminaban por no ajustarse a los criterios clasicistas, a pesar de que partían de ellos, lo que daba lugar a variaciones dentro del canon lírico áureo. En las obras que tratan los siguientes estudios, por su mismo formato y por el hecho de no tener conciencia de estar haciendo historia literaria, vemos que tales criterios no solo se relajan, sino que a veces incluso hasta desaparecen. El artículo que abre la serie está escrito por Ângel Estévez Molinero y lleva por título «En los márgenes de la historiografía, con las poesías amontonadas en el Caxón de sastre (1760-1761)». El autor estudia las publicaciones de este periódico fundado por Francisco Mariano Nifo en 1760. Primero lo sitúa haciendo un breve repaso del origen del periodismo en España y de su relación con la literatura, en especial con los escritores. A partir de ahí, se interesa por la particular selección de poesías que hace este periódico, el cual es uno de los más emblemáticos del momento. El resultado del análisis reafirma cuanto se acaba de decir: el periódico intenta ceñirse al gusto neoclásico movido por el patriotismo y antibarroquismo de la época. Ahora bien, esto se queda solo en una declaración de intenciones, ya que tal selección en muchos casos se corresponde con los gustos de un público más amplio y transversal del que forman los autores ilustrados. Otro tanto cabe decir del artículo de María José Osuna Cabezas «Canonización de la poesía del Siglo de Oro en la labor periodística de Valladares», aunque, en este caso, como se señaló con anterioridad, el gusto ilustrado se halle completamente ausente. La estudiosa trata también de la recepción de la poesía áurea en la prensa periódica, pero atendiendo a la figura del poeta, periodista y dramaturgo Antonio de Valladares Sotomayor; traza un breve recorrido de los distintos periódicos que fundó o en los que colaboró a lo largo de su vida, añadiendo una mínima caracterización de la historia y del contenido de cada uno de ellos. El resultado de la investigación es que se trata de cuatro periódicos que se limitan única y exclusivamente a hacer acopio de textos de prosa política y social los cuales se hallaban por entonces olvidados. Por último, el estudio de Inmaculada Osuna "Consideraciones sobre el canon de la poesía áurea en la educación literaria (1700-1857)» se interesa también por el tema de la recepción, pero visto esta vez desde el ámbito de los textos escolares. Primeramente, la autora traza un panorama general de la enseñanza de la literatura durante el periodo estudiado teniendo en cuenta algunas de sus limitaciones; como, por ejemplo, el hecho de que no hubiera un plan de estudios normalizado ni existiera tampoco una asignatura de historia literaria; por ello, se centra solo en algunos de los manuales más emblemáticos de la época y los compara tanto en la selección que hacen de los autores como en su peculiar modo de abordarlos críticamente. Se 
trata de las Lecciones sobre la Retórica y las Bellas Letras de Hugo Blair (1798-1801), traducidas por José Luis Munárriz, y el Arte de hablar en prosa y en verso (1826) de José Gómez Hermosilla. Osuna contrasta la visión ofrecida por estos dos manuales con la que caracteriza el Breve tratado de poesía latina y castellana de Andrés Merino de Jesucristo, que se había publicado en 1781, pero que se reeditó dos veces en 1818 y 1819. A pesar de que no parece haber sustanciales variaciones en la configuración del canon - recordemos que nos encontramos en aquella segunda y tercera fase en la que José Checa admitía una gradual asimilación de los poetas del Barroco-, la continuidad cronológica que separa los tres manuales desvela, una vez más, la relajación que se produce en la aplicación de los criterios neoclásicos y su consecuente influjo en la manera de encarar algunos autores del siglo XVII, cuya obra se va a ver progresivamente revalorizada.

A partir de aquí, hasta acabar el volumen, los demás artículos se centran en el estudio de obras historiográficas que se publican en Francia e Italia. El interés que tienen estas obras, más allá del tema puramente historiográfico, se debe al hecho de que sirvieron, como reacción patriótica, para dar a conocer la tradición literaria española y defenderla ante las críticas extranjeras. El primer artículo, de Flavia Gherardi, estudia la antología de Juan Francisco Masdeu Poesie di ventidue autori spagnoli del Cinquecento (1786). Masdeu quiere demostrar que son falsas e infundadas las afirmaciones que niegan la aportación cultural española al contexto de las naciones europeas; para ello, hace una selección de algunos de nuestros autores e intenta justificar su presencia en el canon siguiendo el gusto neoclásico de la época. El resultado es que la selección no acaba de ceñirse al criterio empleado, en parte por el sustrato nacionalista que alienta la obra, en parte por el propio gusto del autor, que selecciona aquellas partes de la producción poética que, según él, serían asimilables a la noción de «buen gusto», lo que permite, a la postre, la entrada de los poetas barrocos. El trabajo de Maria D’Agostino "La Colección de poesías castellanas de Giovan Battista Conti: algunos ejemplos de traducción» se distingue del anterior en tanto en cuanto el primero aborda la figura de un español residente en Italia, mientras en este otro ocurre justo lo contrario. Por lo demás, la intención de Conti, igual que la de Masdeu, es demostrar que las críticas vertidas sobre la poesía castellana carecen de fundamento y no se corresponden con la realidad. En opinión de Conti, la mala imagen de España se debe a su profundo desconocimiento. Es por eso que el autor, que conocía bien la tradición literaria española, ya que pasó mucho tiempo en Madrid, lleva a cabo una traducción en verso toscano de algunas de nuestras poesías más emblemáticas. Por su parte, d’Agostino, además de comentar la selección establecida por Conti, estudia el contenido de esas traducciones y las compara con el original. El último artículo, que da fin al conjunto del volumen y a esta serie de obras historiográficas, está escrito por Frédéric Prot y se titula "Asociar al Parnaso español con el francés". La primera colección hispano-francesa de poesías del Siglo de Oro: Espagne poétique (1826-1827) de Juan María Maury». Se distingue de los dos anteriores tanto por el contexto geo- 
gráfico como cronológico de la publicación (recordemos que también este segundo volumen avanza según el orden de publicación de las obras). En este caso, nos encontramos con una Francia que, a comienzos del siglo XIX, ha perdido buena parte de su preeminencia cultural y debe regenerar su poesía con nuevas formas métricas; es por este motivo que empieza a cambiar su visión de la literatura espańola: «La preeminencia cultural que se había arrogado cede ahora no solamente a la curiosidad por otras formas literarias sino también a la necesidad de regenerarse. El gusto del público repercute la revaloración de la literatura española en los círculos letrados y académicos» (p. 333). Es dentro de este contexto que el poeta malagueño Juan María Maury publica su antología bilingüe Espagne poétique (1826-27). Prot señala algunos aspectos relativos al contenido de la obra y a la selección que hace Maury los cuales se relacionan con el contexto antes mencionado; como, por ejemplo, el hecho de que el autor, por su condición misma de poeta a caballo entre dos tradiciones, la clásica y la romántica, busca conciliar las formas métricas del clasicismo francés con aquello que se percibe como extranjería. De este modo, Maury hace también de mediador entre dos culturas: le da a Francia la oportunidad de regenerarse con formas procedentes de su país de origen y permite también que la poesía española entre en el canon europeo con una colección de sus autores más representativos.

Para terminar, parece válida para los dos volúmenes reseñados la idea planteada por los discípulos de López Bueno de que es el diálogo lo que caracteriza la trayectoria del grupo PASO hasta convertirse en su seña de identidad. Según se ha expuesto, ambos volúmenes son el resultado de ese diálogo que se concretó en varios Encuentros Internacionales, pero que se traslada aquí a un espacio bibliográfico. Vale la pena retener esta idea porque tanto Aurea poesis como Entre sombras y luces no pretenden hacer pedagogía; exigen un lector participativo que se sitúe en su mismo plano y que dialogue con ellos: en un caso, sobre el tema concreto de la recepción de la poesía áurea en el siglo xVIII y XIX; y, en el otro, a partir de una variedad de temas, que, además de informarle, dará al lector también la oportunidad de seguir ahondado en alguno de ellos. 
